\title{
Observations on the Rheological Response of Alkali Activated Fly ash Suspensions: The Role of Activator Type and Concentration
}

\author{
Kirk Vance $\left({ }^{\dagger}\right)$, Akash Dakhane $\left({ }^{\ddagger}\right)$, Gaurav Sant $\left({ }^{\S},{ }^{* *}\right)$, Narayanan Neithalath $\left({ }^{+* *}\right)$
}

\section{ABSTRACT}

This paper reports the influence of activator type and concentration on the rheological properties of alkali activated fly ash suspensions. A thorough investigation of the rheological influences (yield stress and plastic viscosity) of several activator parameters, including: (i) the cation type and concentration of alkali hydroxide, and (ii) the alkali-to-binder ratio (n) and silica modulus $\left(M_{s}\right)$, and (iii) the volume of the activation solution, on the suspension rheology is presented. The results indicate a strong dependence on the cation and its concentration in the activation solution. The viscosity of the activation solution and the volumetric solution-to-powder ratio are shown to most strongly influence the plastic viscosity of the suspension. The suspension yield stress is predominantly influenced by the changes in fly ash particle surface charge and the ionic species in the activator. A shift from non-Newtonian to Newtonian flow behavior is noted in the case of silicate-based suspensions for $M_{s} \leq 1.5$. This behavior, which is not observed at higher $M_{s}$ values, or when the fly ash is dispersed in hydroxide solutions or pure water, is hypothesized to be caused by colloidal siliceous species present in this system, or surface charge effects on the fly ash particles. Comparisons of the rheological response of alkali activated suspensions to that of portland cement-water suspensions are also reported.

Keywords: Geopolymer, Rheology, Fly Ash, Yield Stress, Plastic Viscosity

\footnotetext{
${ }^{\dagger}$ School of Sustainable Engineering and the Built Environment, Arizona State University, Tempe AZ 85287 (kevance@asu.edu)

${ }^{\ddagger}$ School of Sustainable Engineering and the Built Environment, Arizona State University, Tempe AZ 85287 (adakahne@asu.edu)

$\S$ Department of Civil and Environmental Engineering, University of California Los Angeles, Los Angeles, CA, gsant@ucla.edu

** California Nanosystems Institute,, University of California Los Angeles, Los Angeles, CA

${ }^{++} *$ School of Sustainable Engineering and the Built Environment, Arizona State University, Tempe AZ 85287 (Narayanan.Neithalath@asu.edu); Corresponding Author. Phone: 001-480-965-6023; Fax: 001-480-965-0557
} 


\section{NOMENCLATURE}

\begin{tabular}{|l|l|}
\hline $\mathrm{n}$ & ratio of $\mathrm{Na}_{2} \mathrm{O}$ in the activator to the total fly ash content \\
\hline $\mathrm{M}_{\mathrm{s}}$ & ratio of $\mathrm{SiO}_{2}$-to- $\mathrm{Na}_{2} \mathrm{O}$ in the activator \\
\hline$\left(\mathrm{a}_{\mathrm{s}} / \mathrm{p}\right)_{\mathrm{v}}$ & $\begin{array}{l}\text { Activation solution-to-powder ratio, by volume (Refer to the definition of } \\
\text { activation solution in 2.1 }\end{array}$ \\
\hline$\left(\mathrm{a}_{\mathrm{s}} / \mathrm{b}\right)_{\mathrm{v}}$ & Activation solution-to-binder ratio, by volume; binder implying fly ash here \\
\hline$(\mathrm{w} / \mathrm{s})_{\mathrm{m}}$ & Water-to-solids ratio, mass-based (Refer to the definition of solids in 2.1) \\
\hline $\mathrm{w} / \mathrm{c}$ & Water-to-cement ratio, mass-based, for OPC systems \\
\hline$\tau$ & Shear stress, Pa \\
\hline$\tau_{\mathrm{y}}$ & Yield stress, Pa \\
\hline$\eta_{\mathrm{p}}$ & Plastic viscosity, Pa.s \\
\hline$\eta_{\mathrm{a}}$ & Apparent viscosity, Pa.s \\
\hline$\dot{\gamma}$ & Shear rate, $\mathrm{s}^{-1}$ \\
\hline
\end{tabular}

23 


\subsection{INTRODUCTION}

Ordinary portland cement (OPC) based concrete is one of the most widely used materials globally, and production of OPC has been shown to require a significant quantity of energy and release significant quantities of $\mathrm{CO}_{2}$. One of the sustainable alternatives to OPC that has been gaining attention is the use of geopolymeric or alkali activated materials, where alumino-siliceous wastes/by-products such as fly ash or slag can be activated using alkalis to create a binding medium that is X-ray amorphous and has a threedimensional network structure (Palomo et al. 1999; Puertas and Fernández-Jiménez 2003; Škvára et al. 2009). The formation of the binding gel is a complex process including the dissolution process where $\mathrm{Si}$ and Al from the source materials are dissolved into a highly alkaline solution, precipitation of aluminosilicate gel, and further polymerization and condensation to develop the final microstructure (Davidovits 1999; Davidovits 2005). Geopolymeric systems are reported to demonstrate similar or superior mechanical and durability properties compared to OPC-based concretes (Bijen 1996; FernándezJiménez et al. 2007; Bernal et al. 2012). Geopolymers based on coal fly ash are of particular interest because of the potential utilization of a waste material that is available in large quantities as well as the beneficial properties of the resulting binder (Provis et al. 2007).

While several studies have examined the mechanical/durability properties of fly ash-based geopolymers, there have been very few studies on aspects related to their rheological response. A few studies have investigated the flow behavior of fly ash-based geopolymers using conventional concrete workability techniques (Qing-Hua and Sarkar 1994; Poulesquen et al. 2013) and investigated the influence of superplasticizing admixtures on the rheology of these systems (Termkhajornkit and Nawa 2004; Criado et al. 2009; Palacios et al. 2009; Burgos-Montes et al. 2012). Superplasticizers are superfluidificants which are typically composed of polar chain polymers which act as both deflocculant and suspension stabilizer (Pasquino et al. 2013). The charged polymers adsorb on the surface of cement grains acting to disperse cement particles and breakup agglomerations, freeing water in the suspension and enhancing flowability while enhancing the stability of the particles in suspension (Cyr et al. 2000; Papo and Piani 2004; Mikanovic and Jolicoeur 2008). Studies on the influence of superplasticizers on the flowability of geopolymer suspensions have generally found mixed results (Criado et al. 2009; Palacios et al. 2009), indicating that the nature of these suspensions is likely different from that of OPC suspensions.

This paper aims to build improved understanding of the rheology of fly ash activated geopolymers and explore the influence of activator type and composition on their rheological properties. Two different classes of activators are used in this study where Class F fly ash is used as the principal solid precursor: (i) 
sodium or potassium hydroxide, and (ii) sodium or potassium silicate, whose solutions in water are conditioned to different $\mathrm{SiO}_{2}-\mathrm{M}_{2} \mathrm{O}$ ratios $\left(\mathrm{M}_{s}\right)$ and $\mathrm{M}_{2} \mathrm{O}$-to-fly ash powder ratios $(n)$, where $\mathrm{M}$ is the cation. The rheological parameters considered are the yield stress and plastic viscosity of the suspensions determined using the well-known Bingham model. Obtaining a detailed understanding of the rheological influences of alkali cation type and activation solution viscosity is emphasized. Additionally an in-depth investigation of the rheology is attempted using a wide shear range method as illustrated in (Vance, Kirk 2014), where model-less estimations of rheological parameters are achieved. This experimental approach is used to compare the rheological nature of these suspensions to those of OPC-water suspensions. Limited shear stress growth rheological studies are described in an effort to discern the transition between Newtonian and non-Newtonian behaviors with changing silicate activator chemistry.

\subsection{EXPERIMENTAL PROGRAM}

\subsection{Experimental Parameters}

A Class F fly ash conforming to ASTM C 618 (2013) was used as a solid precursor. The chemical composition of fly ash as determined using x-ray fluorescence (XRF) is shown in Table 1; the residual quantity represents the impurities and other compounds which cannot be identified through XRF. The specific surface area (SSA) of fly ash was measured to be $218 \mathrm{~m}^{2} / \mathrm{kg}$ using Blaine's air permeability apparatus. The median particle size, measured using the dynamic light scattering method was $19.9 \mu \mathrm{m}$. The loss on ignition (LOI) of the fly ash is determined by measuring the mass loss of the fly ash powder between $105^{\circ} \mathrm{C}$ and $1000^{\circ} \mathrm{C}$.

Table 1: Chemical composition and physical properties of fly ash

\begin{tabular}{|c|c|c|c|c|c|c|c|c|c|}
\hline $\mathrm{SiO}_{2}$ & $\mathrm{Al}_{2} \mathrm{O}_{3}$ & $\mathrm{Fe}_{2} \mathrm{O}_{3}$ & $\mathrm{CaO}$ & $\mathrm{MgO}$ & $\mathrm{SO}_{3}$ & $\mathrm{Na}_{2} \mathrm{O}$ & $\mathrm{K}_{2} \mathrm{O}$ & LOI & $\mathrm{SSA}$ \\
\hline $58.4 \%$ & $23.8 \%$ & $4.19 \%$ & $7.32 \%$ & $1.11 \%$ & $0.44 \%$ & $1.43 \%$ & $1.02 \%$ & $0.5 \%$ & $218 \mathrm{~m}^{2} / \mathrm{kg}$ \\
\hline
\end{tabular}

The activators used were hydroxide or silicate solutions of $\mathrm{Na}$ or K. The concentration of $\mathrm{NaOH}$ and $\mathrm{KOH}$ solutions used was $4 \mathrm{M}$ and $8 \mathrm{M}$. The activation solution refers to the solution of water and the alkali salt(s): alkali hydroxide and/or alkali silicates in which the fly ash is suspended. When silicate-based activators are used, this includes the solids content in the activator solution, the water content in the activator solution, and the additional water required to obtain the desired water-to-powder ratio. In other words, i.e., the activation solution is the suspending fluid. The activation solution-to-fly ash ratio (mass-basis) used was 0.35 corresponding to a volumetric ratio of activation solution-to-powder $\left(a_{s} / p\right)_{v}$ of between 0.85 and 0.90 . The $\mathrm{Na}$ - and $\mathrm{K}$-silicate solutions for activation were proportioned considering two parameters: (i) $\mathrm{n}$ - the ratio of $\mathrm{Na}_{2} \mathrm{O}$ in the activator to the total fly ash content; and (ii) $\mathrm{M}_{\mathrm{s}}$ - the ratio of 
$\mathrm{SiO}_{2}$-to- $\mathrm{Na}_{2} \mathrm{O}$ in the activator. Two different $\mathrm{n}$ values were used: 0.03 and 0.05 . The mass-based $\mathrm{M}_{\mathrm{s}}$ values of the as-obtained $\mathrm{Na}$ - and K-silicates were 3.22 and 2.10 respectively, which corresponds to mole-based values of 3.32 and 3.29 . The solids content in the silicate solutions was approximately $36 \%$. Requisite amounts of $\mathrm{NaOH}$ or $\mathrm{KOH}$ were added to the silicate solutions to adjust the $\mathrm{M}_{\mathrm{s}}$ (mole-based) to 2.5 or 1.5 for both $\mathrm{Na}$ - and $\mathrm{K}$-silicate solutions. $\mathrm{M}_{\mathrm{s}}$ values in this range have been shown to be necessary to induce sufficient activation and strength development (Ravikumar and Neithalath 2012b; Ravikumar and Neithalath 2012a). For the Na- and K-silicate activated fly ashes, the mass-based water-to-solids ratio $(\mathrm{w} / \mathrm{s})_{\mathrm{m}}$ - used was 0.20 and 0.25 which corresponds to $a\left(a_{s} / p\right)_{v}$ between 0.59 and 0.74 and between 0.72 and 0.88 respectively. The solids in $(\mathrm{w} / \mathrm{s})_{\mathrm{m}}$ consists of fly ash, the solid fraction of the K- or Na-silicate activator, and the solid fraction of the alkali hydroxide used to adjust the $M_{s}$, and the liquid consists of the water in the activator solution and the water added to achieve at the desired $(\mathrm{w} / \mathrm{s})_{\mathrm{m}}$. In order to facilitate comparisons between the rheological performances of these suspensions, it may be necessary to consider the solid loading on a volume basis. Hence in the discussion section, the actual volume-based activation solution-to-powder ratios - $\left(a_{s} / p\right)_{v}$ for the corresponding $(w / s)_{m}$ are used. An OPC suspension proportioned at a mass-based water-to-cement ratio $(\mathrm{w} / \mathrm{c}$ ) of 0.45 (which corresponds to a w/c of 1.42 on a volume-basis), was also proportioned so as to provide a point of comparison of fly ash geopolymer rheology to those of commonly used OPC systems.

\subsection{Mixing and Testing Procedure}

102

Liquid activators were prepared prior to mixing with the binder (fly ash), and allowed to cool down for a period of 3 to 4 hours to ambient temperature $\left(22 \pm 2^{\circ} \mathrm{C}\right)$ as measured with an infrared thermometer. For the rheological studies of activation solutions, approximately $12 \mathrm{~mL}$ of solution was placed using a disposable syringe in a TA Instruments AR2000EX rheometer in the concentric cylinder configuration, in which both the cup and bob were textured, to reduce slip. The gap between the concentric cylinders was fixed at $1.0 \mathrm{~mm}$. For studies of fresh geopolymer suspensions, approximately $200 \mathrm{~g}$ of the suspension was mixed using a kitchen blender as follows: (1) initial hand mixing to disperse the powder in the activation solution and to ensure that particles do not adhere to the edges of mixing container, (2) mixing in the blender at high speed for 30s, (3) 30s covered rest period, and (4) final mixing at high speed in the blender

111 for 30s. This mixing sequence is a modification to ASTM C1738 (2011) which provides recommendations

112 for measurements of cement paste rheology (Nehdi and Rahman 2004); but has been demonstrated to 113 provide similar fluidity and mixing consistency. After mixing, approximately $6 \mathrm{~mL}$ of sample was extracted 114 using a disposable syringe and placed in the rheometer in the parallel plate configuration. The gap 
between the top and bottom plates parallel plates (top plate diameter of $50 \mathrm{~mm}$, serrated to a depth of $1.0 \mathrm{~mm}$ ) was set to $2.0 \mathrm{~mm}$ during the experiments, as this gap has been noted to provide consistent results in cementitious suspensions (Vance, Kirk 2014). The bottom plate was serrated to a depth of 0.15 $\mathrm{mm}$. Shearing surfaces were serrated to minimize the effects of slip and localized particle migration from the shearing surface (Mannheimer 1983; Saak et al. 2001). Shearing surfaces were serrated to different depths to avoid the serrations of the upper and lower geometries from keying into each other, resulting in an incorrect gap as well as potentially damaging the rheometer. The rheological studies were carried out with the Peltier plate set to a temperature of $25 \pm 0.1{ }^{\circ} \mathrm{C}$. The approximate time from the addition of the activation solution to the start of the rheological experiment was $150 \mathrm{~s}$. Treatment and conditioning of experimental data was carried out for shear stress and shear rates using the TA Instruments TRIOS software package. For all rheological experiments, three replicate suspensions were generated and studied, and experimental duration was set to minimize potential effects of sedimentation.

The general experimental procedure consists of varying the shear rate as follows: (1) a stepped ramp-up pre-shear phase, (2) a subsequent stepped ramp-up, and (3) a stepped ramp-down phase. The actual data acquisition is carried out during steps (2) and (3). Shear stress values are recorded every second, with a given shear step being terminated when a steady state has been achieved, as defined by 3 consecutive measurements within $5 \%$ of each other. For all the studies, the values used in determining rheological properties are the steady state values of shear stress and the related shear rate in the down ramp. Two different rheological evaluations are conducted. The shear rate range used for the studies of activation solutions and the suspension was 5-to-100/s, hereinafter referred to as the "normal" shear rate range. This is the shear rate range that is used in a majority of rheological studies on cementitious suspensions (Nehdi and Rahman 2004; Banfill 2006). For the comparative study of geopolymer and cementitious suspensions, a "wide" shear rate range: 0.005 -to-100/s was used. The "wide" experiment follows a recent study (Vance, Kirk 2014) in an effort to characterize and adequately model the stress plateau which only manifests are very lower shear rates (Barnes 1999). A graphical representation of the two rheological procedures used in this study is presented in Figure 2. In addition, an oscillatory shear stress growth study was carried out to investigate the unexpected Newtonian behavior when an activation solution with a low(er) $M_{s}$ was used. Here, a coaxial cylinder geometry was used with an oscillatory frequency of $1 \mathrm{~Hz}$ and a stress range from $0.005 \mathrm{~Pa}$ to $50 \mathrm{~Pa}$ was employed. Stress ranges below $0.1 \mathrm{~Pa}$ resulted in torque readings that were close to the torque limit of the instrument, resulting in significant data scatter and thus such data is disregarded in the analysis. 

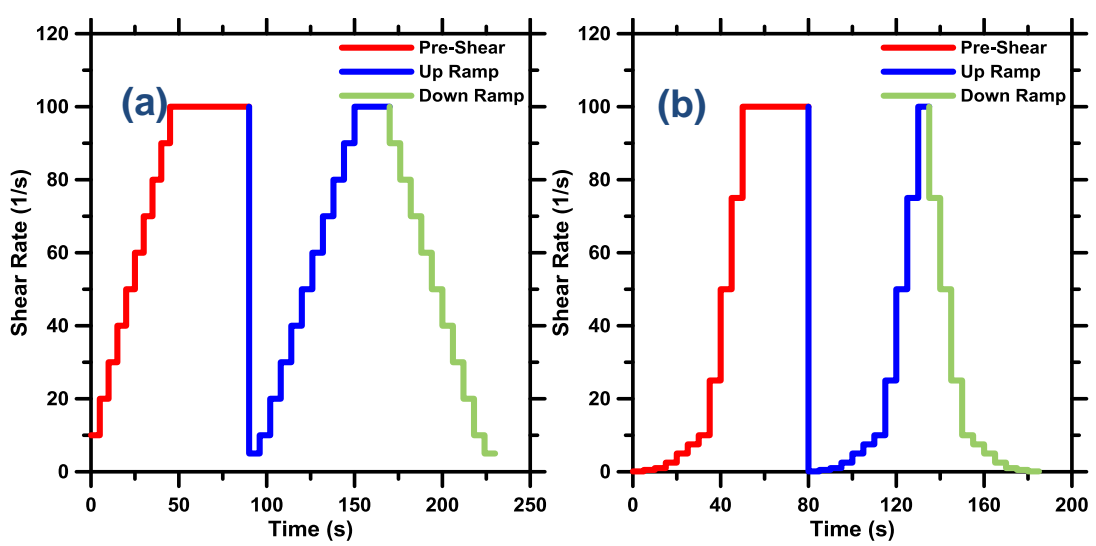

Fig. 1 Rheological procedure: (a) "normal" shear range and (b) "wide" shear range

The viscosity of the activation solutions was determined by fitting the rheological data to the Newtonian flow model shown in Equation 1. The rheological model parameters for the "normal" shear rate range (5to-100/s) for geopolymer suspensions was calculated by fitting the down-ramp data to the Bingham model shown in Equation 2 (Bingham 1922). The use of Bingham and Newtonian models and their adequacy (or lack thereof) is better considered by analysis of additional data provided via "wide" shear rate range studies. In the equations below, $\tau$ is the shear stress $(\mathrm{Pa}), \tau_{y}$ is the yield stress $(\mathrm{Pa}), \eta_{p}$ is the plastic viscosity (Pa.s), and $\dot{\gamma}$ is the shear rate $\left(\mathrm{s}^{-1}\right)$.

Newtonian: $\quad \tau=\eta_{a} \dot{\gamma}$

Equation (1)

Bingham:

$$
\tau=\tau_{y}+\eta_{p} \dot{\gamma}
$$

Equation (2)

\subsection{RESULTS AND DISCUSSIONS}

This section discusses the influence of the type and chemistry of the alkaline activation solution on the rheological parameters of fly ash suspensions determined using the Bingham model. The solution is also evaluated in itself to account for the influences of ion concentrations on solution viscosity, which in turn influences the rheological properties of the suspension.

\subsection{Rheological Behavior of the Activation Solutions}

The rheology of the activation solutions was evaluated in the "normal" shear rate range (5-to-100/s). 4M and $8 \mathrm{M} \mathrm{NaOH}$ and $\mathrm{KOH}$ solutions were used to explore the influence of concentration and cation type on flow properties. Additional experiments were carried out using $\mathrm{Na}$-and-K- silicate solutions to investigate the influence of $n, M_{s}$ and cation type on solution rheology, and for comparison with hydroxide solutions. 
Expectedly, all of the activation solutions demonstrated Newtonian behavior over the range of shear rates investigated.

The influences of alkali cation, molarity, and $n$ and $M_{s}$ respectively on the solution viscosity are presented

171 in Figures $2(a-b)$. For reference, the viscosity of water at $25^{\circ} \mathrm{C}$ is approximately $8.9 \times 10^{-4}$ Pa.s. Na-

172 containing solutions demonstrate higher viscosities than the K-containing ones over all values of $n$ and $M_{s}$

173 considered, which is in line with reports in the literature (Provis and Van Deventer 2009). The error was determined to be less than $2 \%$ on replicate measurements for the activation solutions and less that $5 \%$ for the alkali activated fly ash pastes on replicate measurements.
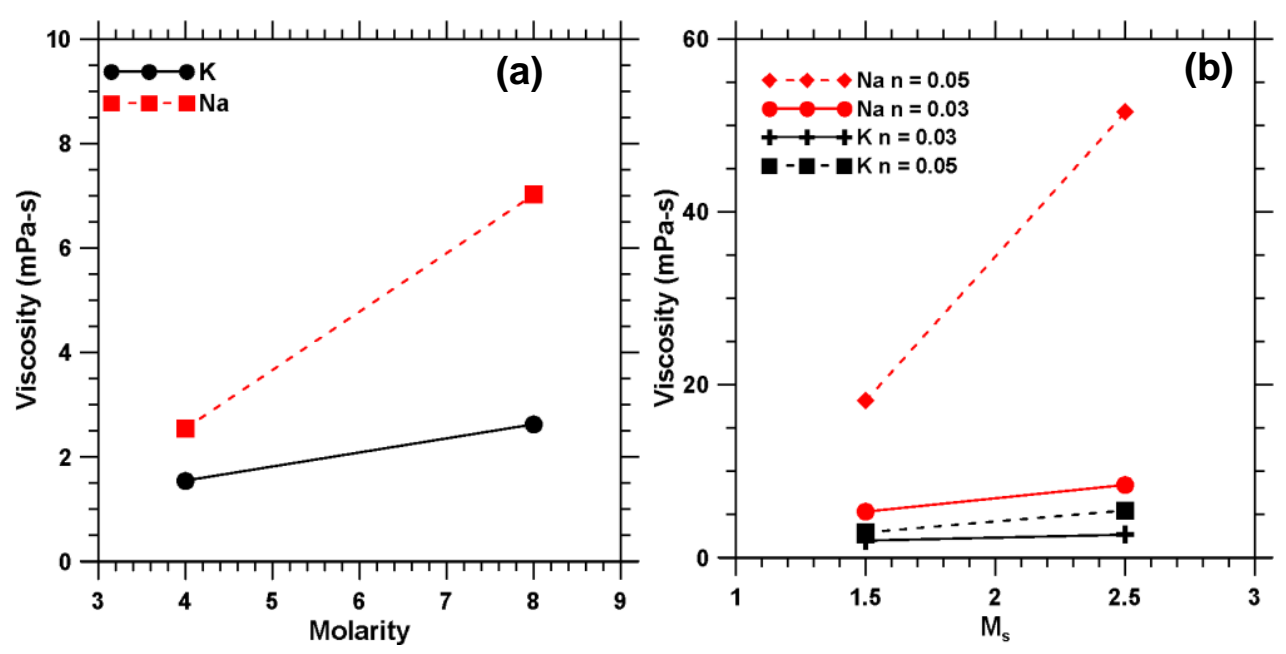

178

179

180

181

182

183

184

185

186

187

188

189

Fig. 2 Influence of: (a) molarity of $\mathrm{KOH}$ and $\mathrm{NaOH}$ solutions on its viscosity, and (b) $n, \mathrm{M}_{\mathrm{s}}$ of K-silicate and Na-silicate activators on its viscosity. The viscosities were extracted using a Newtonian model.

From Figure 2(a) two obvious trends emerge: increasing concentration increases the solution viscosity regardless of the cation type, and $\mathrm{Na}$-based activators result in significantly higher viscosities compared to K-based activators, at equivalent concentrations. As an example: at a concentration of $8 \mathrm{~mol} / \mathrm{L}$, the viscosity of the $\mathrm{NaOH}$ solution is 3 times higher than the corresponding $\mathrm{KOH}$ solution. The viscosity of aqueous solutions is described by ion-ion interactions and ion-dipole forces. As the ionic concentration increases, the influence of ion-dipole forces increases, resulting in an increase in the measured viscosity. The higher charge density of $\mathrm{Na}^{+}$ions results in higher ion-dipole forces in the $\mathrm{NaOH}$ solution, thereby increasing their viscosity relative to the $\mathrm{KOH}$ solution.

When silicate bearing activators are used, a similar trend with respect to the alkali cation is noted (Figure $2 b)$. In addition, a general increase in viscosity with increasing $M_{s}$ and $n$ is observed, with the effect once again being more noticeable for the Na cation than for K. NMR studies of concentrated alkali silicate 
solutions have indicated the presence of colloidal Si-O-H-M complexes (where $\mathrm{M}$ denotes $\mathrm{Na}$ or $\mathrm{K}$ species) on the order of $0.6 \mathrm{~nm}$ in size, which form aggregates on the order of a few $\mathrm{nm}$ (Stebbins et al. 1992; Tognonvi et al. 2010), the presence of which increases the solution viscosity (Brady 1993). The quantity/size of these colloidal species and aggregates likely increases with $M_{s}$ due to an increased Si (i.e., complex) content and the reduced abundance of $\mathrm{OH}^{-}$species to break Si-O-Si bonds (Iler 1979), which results in an increase in the solution viscosity (Svensson et al. 1986; Wijnen et al. 1989). On the other hand, an increase in $\mathrm{n}$ increases the ionic concentration of $\mathrm{Na}$ or $\mathrm{K}$, and $\mathrm{Si}$ species in the solution, resulting in increased ion-dipole forces and an increased quantity of Si-O-H-M complexes. In addition, to obtain identical $n$ and $M_{s}$ values for $\mathrm{Na}$ and $\mathrm{K}$ silicate solutions, more Na-silicate is needed (than K-Silicate) due to the lower molecular weight of sodium. This results in inequivalent ion-dipole forces in these solutions, as a result of which $\mathrm{Na}$-bearing silicate solution show higher viscosities. Figure 2(b) also shows that, with an increasing value of $n$, the viscosity enhancement is higher with increasing $\mathrm{M}_{s}$ when $\mathrm{Na}^{+}$is the cation in solution. This behavior is attributed to the more significant influence of ion-dipole forces with smaller, more charge dense $\mathrm{Na}^{+}$ions combined with higher colloidal species concentration.

\subsection{Rheological Behavior of Fly Ash Suspensions Activated with $\mathrm{NaOH}$ or $\mathrm{KOH}$}

Rheological studies were performed on suspensions where fly ash was dispersed in $\mathrm{NaOH}$ or $\mathrm{KOH}$ solutions (4M and $8 \mathrm{M}$ ) using the "normal" shear rate range protocol described in Section 2. From Figure 3 it is observed that increasing the activation solution concentration results in an increase in the plastic viscosity and yield stress of the suspensions. This behavior is primarily attributed to the increase in the viscosity of the activation solution with concentration. Similarly, the effect of the cation on the rheological performance of the suspension can also be related to the rheology of the medium in which the fly ash is dispersed. As seen in Figure 2(a), $\mathrm{NaOH}$ solutions demonstrate higher viscosity than the $\mathrm{KOH}$ solutions. The change in plastic viscosity of the fly ash- $\mathrm{NaOH}$ suspension as compared to the fly ash- $\mathrm{KOH}$ suspension when the concentration increases also mimics trends in the viscosity of the activation solution. Yield stress, however, increases at a greater rate with an increase in activation solution concentration when the fly ash is dispersed in $\mathrm{KOH}$. At low(er) concentrations, the yield stress of the fly ash- $\mathrm{NaOH}$ suspension is higher than that of the fly ash-KOH suspension, while at higher concentrations, the yield stress values of the two suspensions are similar. The yield stress of a suspension is influenced by several competing effects: (i) the viscosity of the fluid, (ii) interparticle forces (interaction potential or steric forces and van der Waals forces), and (iii) the influence of particle jamming (Barnes 1999; Lowke 2009). As the volume fraction of solids (fly ash) is similar for all these mixtures and the fly ash particles are spherical, the 
222 influence of particle jamming can be ignored in comparative evaluations. Similarly, particle spacing also 223 will be approximately similar across these suspensions, and thus the influence of van Der Waals forces is 224 likely redundant. The yield stress can be considered to be proportional to the inverse square of particle separation (van der Waals forces) minus the square of the interaction potential (zeta potential) (Scales et al. 1998). Increased particle separation will decrease the effect of van Der Waals forces, while a higher net surface charge on the particles will increase the repulsive force between particles, both effects resulting in a decrease in yield stress. This behavior can be conceptually verified by considering the surface interaction effect that results from the use of superplasticizers in cementitious suspensions (Papo and Piani 2004). As such, there remain two influences which may explain the relative increase in yield stress with increasing molarity: interaction potential and viscosity of the activation solution. Studies have shown the zeta-potential of fly ash is dependent on ion type, ion concentration and the $\mathrm{pH}$ of the suspending solution (Nägele 1986; Nägele and Schneider 1989). In solutions of $\mathrm{NaOH}$ and $\mathrm{KOH}$, the zeta potential of fly ash has been shown to be negative, with those in $\mathrm{NaOH}$ solutions showing a larger negative potential (Nägele and Schneider 1989). This behavior is attributed to the enhanced adsorption of $\mathrm{K}^{+}$on the fly ash particle surfaces than $\mathrm{Na}^{+}$ions (Franks 2002), resulting in a less negative surface charge as the $\mathrm{K}^{+}$ concentration is increased. As the zeta potential decreases (i.e., becomes less negative), the yield stress increases due to a decreased repulsive force between fly ash particles. The smaller increase in yield stress in $\mathrm{NaOH}$ solutions as compared to $\mathrm{KOH}$ solutions with increasing molarity can thus be attributed to the greater negative surface charge of fly ash particles in $\mathrm{NaOH}$ that result in more significant repulsive forces.

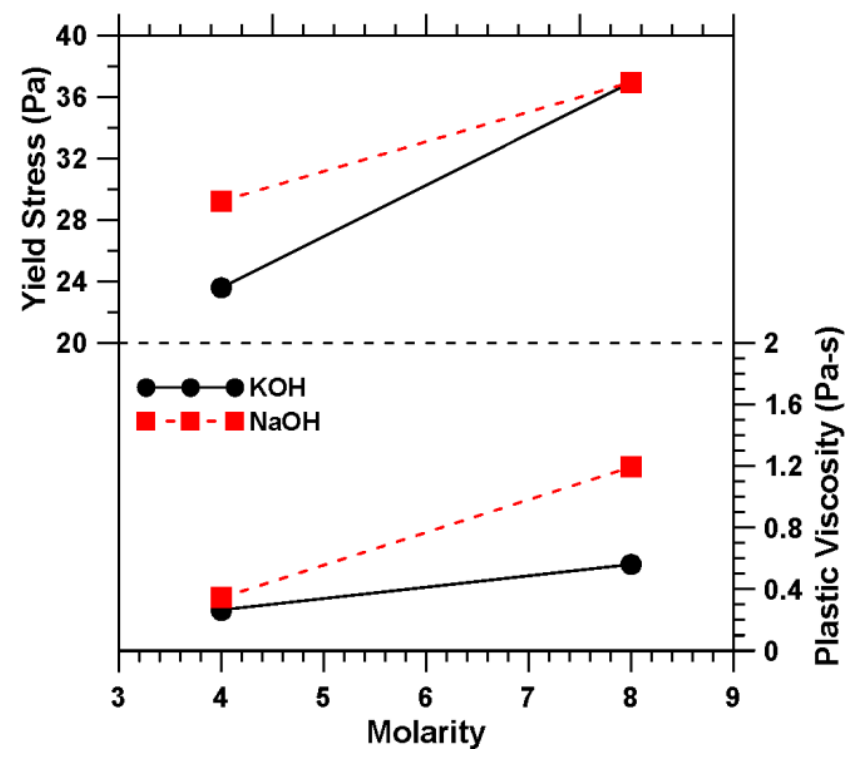

Fig. 3 Influence of molarity of $\mathrm{KOH}$ and $\mathrm{NaOH}$ on the rheological properties determined using the Bingham model 


\subsection{Rheological Behavior of Fly Ash Suspensions Activated using Na- or K-Silicates}

245 The following discussions highlight the major factors influencing the rheological parameters of fly ash 246 suspensions activated using Na- or K-silicate solutions. Two key factors are identified and explored: (i) the viscosity of the suspending media as dictated by the $M_{s}$ of the activator and $n$ of the suspension, and (ii) the volume of activation solution present.

\subsubsection{Influence of $n, M_{s}$ and $(w / s)_{m}$}

Rheological studies were performed on suspensions where fly ash was dispersed in $\mathrm{Na}$ - or K-silicate solutions. For the silicate based activators, $\mathrm{MOH}$ was added to reduce the $\mathrm{M}_{\mathrm{s}}$ of the as-obtained silicate solutions to the desired values ( 1.5 and 2.5 in this study). The rheological studies were performed using the "normal" shear rate range as described in Section 2. Figures 5 and 6 show the influence of $n$ and $M_{s}$ on the yield stress and plastic viscosity of fly ash-K silicate and fly ash-Na silicate suspensions respectively for two different $(\mathrm{w} / \mathrm{s})_{\mathrm{m}}-0.20$ (Figures $4(\mathrm{a})$ and $5(\mathrm{a})$ ) and 0.25 (Figures $4(\mathrm{~b})$ and $5(\mathrm{~b})$ ) corresponding to $(\mathrm{w} / \mathrm{s})_{\mathrm{V}}$ ratios of between 0.57 and 0.74 and between 0.72 and 0.88 for $(\mathrm{w} / \mathrm{s})_{\mathrm{m}}$ ratios of 0.20 and 0.25 respectively. For the Na-silicate activated case, a suspension at a $(\mathrm{w} / \mathrm{s})_{\mathrm{m}}$ of 0.20 could not be proportioned with an $n$-value of 0.05 and $M_{s}$ of 2.5 because the water from the silicate activators themselves produced a $(\mathrm{w} / \mathrm{s})_{\mathrm{m}}$ higher than 0.20 . Increasing the $(\mathrm{w} / \mathrm{s})_{\mathrm{m}}$ from 0.20 to 0.25 results in a drastic decrease in the yield stress and plastic viscosity as would be expected. Increasing the amount of suspending fluid in a suspension increases the particle spacing, thereby increasing the fluid film thickness around the particles, thus decreasing yield stress and plastic viscosity. Increasing the water content also reduces the alkali ion concentration in the solution which reduces the viscosity of the activation solution, further contributing to a decrease in the values of the rheological parameters.
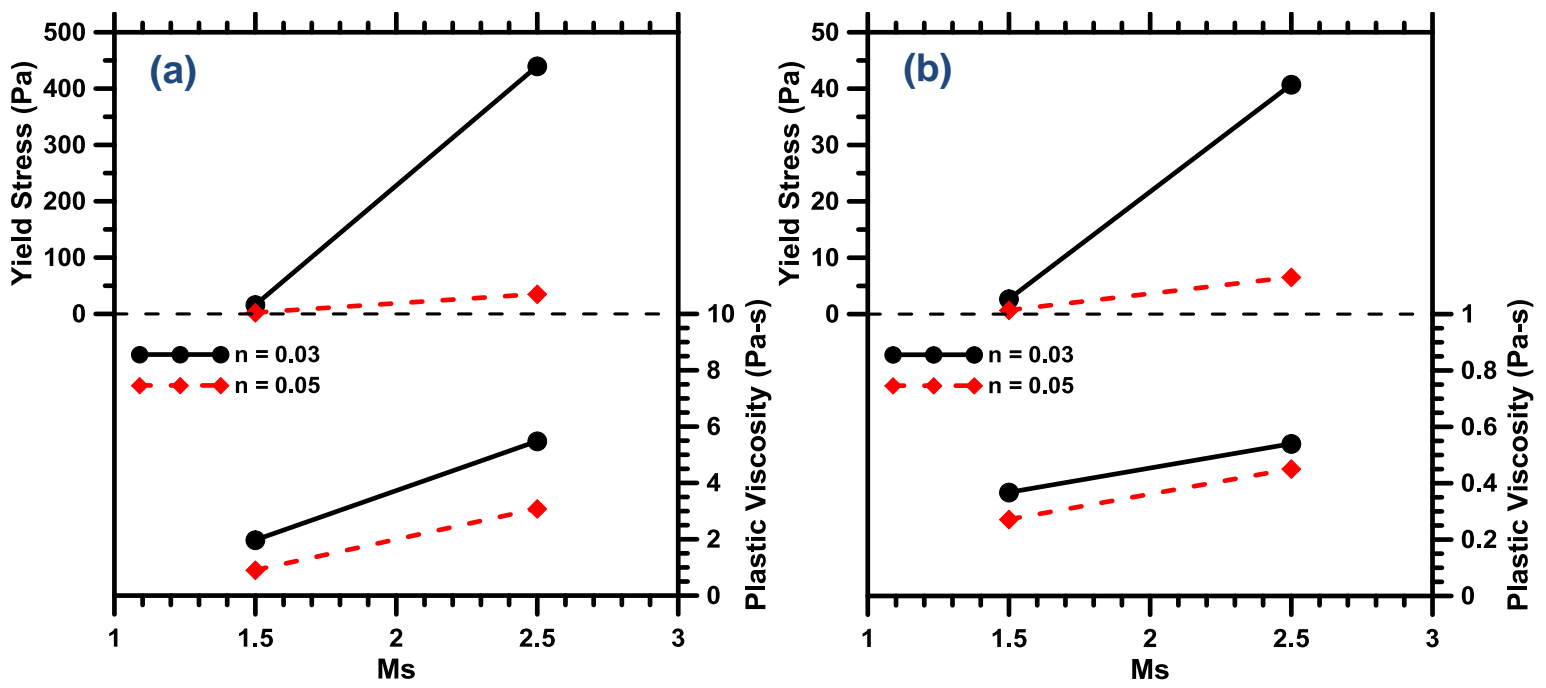
Fig. 4 Influence of $M_{s}$ on the rheological properties of fly ash-K silicate suspensions determined using the Bingham model for: (a) $0.20(\mathrm{w} / \mathrm{s})_{\mathrm{m}}$ and (b) $0.25(\mathrm{w} / \mathrm{s})_{\mathrm{m}}$. Note the difference in the ranges of yield stress and plastic viscosity with changing $(\mathrm{w} / \mathrm{s})_{\mathrm{m}}$. The $\mathrm{Y}$-axis scales are different in both these graphs.
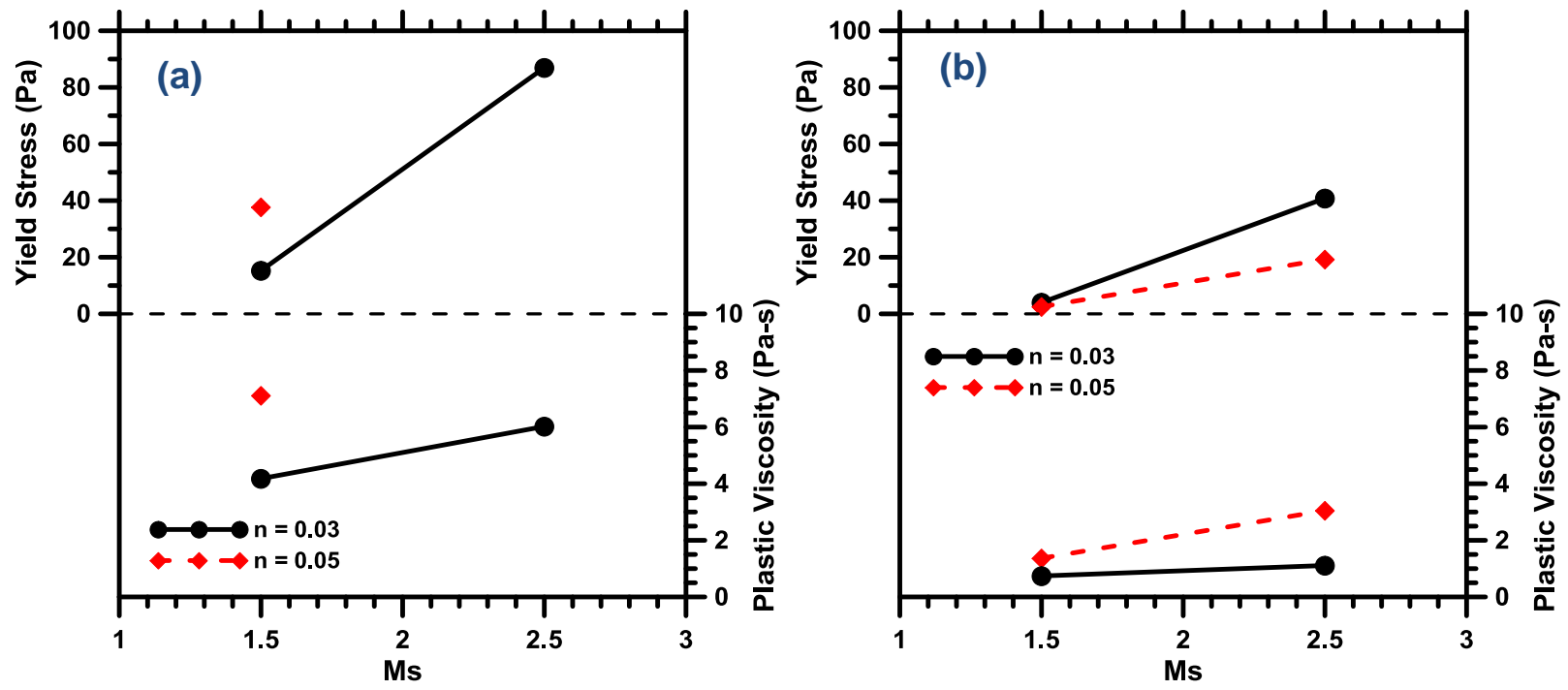

Fig. 5 Influence of $M_{s}$ on the rheological properties of fly ash-Na silicate suspensions determined using the Bingham model for: (a) $0.20(\mathrm{w} / \mathrm{s})_{\mathrm{m}}$ and (b) $0.25(\mathrm{w} / \mathrm{s})_{\mathrm{m}}$. At a $(\mathrm{w} / \mathrm{s})_{\mathrm{m}}$ of 0.20 , a fly ash-Na silicate suspension with an $M_{s}$ of 2.5 and $n$ of 0.05 was not possible because it would have meant removing water from the activators to obtain the desired $(\mathrm{w} / \mathrm{s})_{\mathrm{m}}$.

Several key observations are noted that are typical of these figures: (i) increasing $M_{s}$ results in increases in yield stress and plastic viscosity, (ii) a lower $n$-value results in more significant enhancements in yield stress as $M_{s}$ is increased, and (iii) at low values of $M_{s}$ the yield stress approaches zero suggesting a transition to Newtonian behavior. The increase in the yield stress and plastic viscosity with increasing $M_{s}$ may be partially attributed to the increase in activation solution viscosity with $M_{s}$ as noted in Figure 2 . The latter observations which demand careful examination are explored in the forthcoming sections.

When Figures 4 and 5 are compared, the following important observations can be made: (i) at a lower $(\mathrm{w} / \mathrm{s})_{\mathrm{m}}$ and higher $\mathrm{M}_{\mathrm{s}}$, the yield stress of the fly ash-K silicate suspension is much higher than that of the fly ash-Na silicate suspension, while the values are comparable at a higher $(\mathrm{w} / \mathrm{s})_{\mathrm{m}}$; and (ii) increasing the $(\mathrm{w} / \mathrm{s})_{\mathrm{m}}$ results in a significant reduction in plastic viscosity especially at higher $\mathrm{M}_{\mathrm{s}}$ for the fly ash-K silicate suspension while the reduction is much lower for the fly ash-Na silicate suspension. These observations support the idea that flow parameters are influenced to a great extent by the adsorption of cations on particle surfaces. At higher $(\mathrm{w} / \mathrm{s})_{\mathrm{m}}$, the surface adsorption of ions and van Der Waals forces become less significant as the particle spacing increases, and thus the influence of the alkali cation from the activation solution is reduced. In addition, at higher $(\mathrm{w} / \mathrm{s})_{\mathrm{m}}$, Na-based fly ash suspensions demonstrate similar or higher yield stress as compared to K-based suspensions. Increasing the n-value is shown to decrease both 
the yield stress and plastic viscosity in K-based suspensions, while generally increasing those values in $\mathrm{Na}$ based suspensions (except for the fly ash-Na silicate suspension with an $M_{s}$ of 2.5 at a $(w / s)_{m}$ of 0.25$)$. The increased rheological properties in Na silicate-fly ash suspensions as compared to $\mathrm{K}$ silicate-fly ash suspensions is primarily attributed to the significantly greater viscosity of the Na-based suspensions as compared to K-based suspensions as noted in Figure 2. Furthermore, in K silicate-fly ash suspensions, the behavior is Newtonian (zero yield stress) at low $M_{s}$ values regardless of $(w / s)_{m}$ ratio, whereas the Nasilicate suspensions exhibit the Newtonian behavior only at the higher $(\mathrm{w} / \mathrm{s})_{\mathrm{m}}$. The shift to a Newtonian flow regime at low $M_{s}$ values is explored in detail in a later section.

\subsubsection{Dependence of rheological parameters on the volumetric activator solution-binder ratio}

The $(\mathrm{w} / \mathrm{s})_{\mathrm{m}}$ ratio is a mass-based ratio of the water in the activator (along with any additional water added) to the total solids (the binder material, fly ash in this case and the solids present in any of the activating chemicals) in the suspension. The $\left(a_{s} / b\right)_{v}$ ratio, on the other hand, is the volumetric ratio of the activation solution to the binder. The activation solution implicitly includes the dissolved solids present in the solution: both the silicate solutions used in this study have the same solids content. The use of $\left(a_{s} / b\right)_{V}$ ratio, rather than $(\mathrm{w} / \mathrm{s})_{\mathrm{m}}$ (which is an easier proportioning parameter for practical applications) is deemed to be appropriate because the rheological characteristics of suspensions are typically dependent on the volume of suspending fluid present, the size, shape, and concentration of the suspended particles (Sweeny and Geckler 1954; Jeffrey and Acrivos 1976; Mueller et al. 2010; Santamaria-Holek and Mendoza 2010; Bentz et al. 2012), and the rheology of the suspending medium (Krieger and Dougherty 1959; Kamal and Mutel 1985; Barnes 1989). It is further notable that the use of a constant (w/s) $\mathrm{m}$ while modifying the $n$ and $M_{s}$ values will not result in a constant $\left(a_{s} / b\right)_{v}$ due to the influence of changing amounts of $\mathrm{MOH}$ added to the activator solution to maintain the desired $M_{s}$. Generally, increasing either $M_{s}$ or $n$ will increase the $\left(a_{s} / b\right)_{V}$ ratio due to an increase in solids present in the activator, requiring an increase in solution volume to maintain a constant $(\mathrm{w} / \mathrm{s})_{\mathrm{m}}$ ratio. Thus, at the same $(\mathrm{w} / \mathrm{s})_{\mathrm{m}}$ ratio, an activation solution with a higher $n$ and/or $M_{s}$ will have both a higher $\left(a_{s} / b\right)_{V}$ ratio and a higher added $M^{+}$ion concentration. 

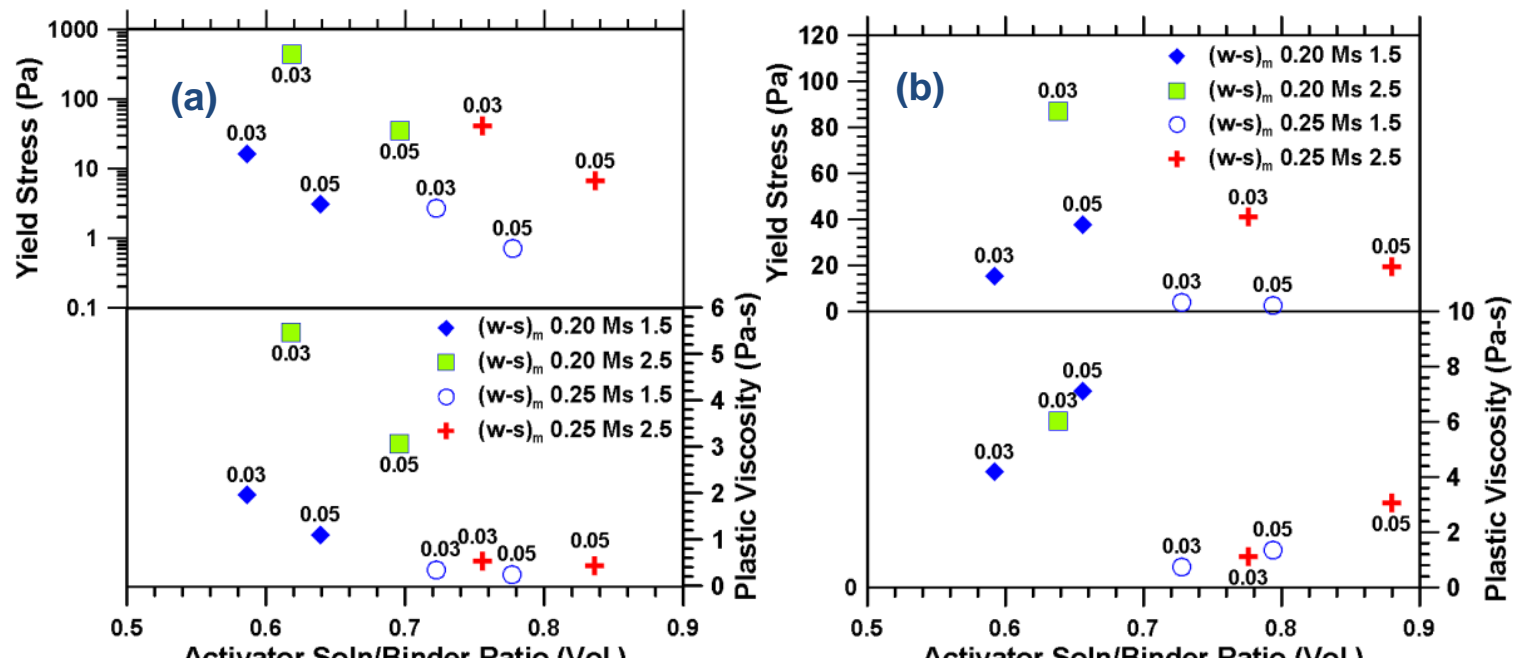

Fig. 6 Influence of $\left(a_{s} / b\right)_{v}$ ratio on rheological properties for: (a) fly ash-K silicate suspensions, and (b) fly ash-Na silicate suspensions (labels in parentheses are the $n$-values).

Figures $6(\mathrm{a})$ and $(\mathrm{b})$ illustrate the influence of $\left(\mathrm{a}_{\mathrm{s}} / \mathrm{b}\right)_{\mathrm{v}}$ on the yield stress and plastic viscosity of $\mathrm{Na}$ - and $\mathrm{K}$ silicate activated fly ash suspensions respectively. In general, the yield stress and the plastic viscosity decrease for all the suspensions as the $\left(a_{s} / b\right)_{v}$ increases, due to the reduction in particle concentration. This is a trend that is expected, as in the case of OPC when the $(w / p)_{v}$ is increased (Ferraris 1999). For both $\mathrm{K}$ - and $\mathrm{Na-based} \mathrm{suspensions,} \mathrm{with} \mathrm{an} \mathrm{increase} \mathrm{in} \mathrm{M}_{\mathrm{s}}$, at the same $\mathrm{n}$ value, it is observed that both the yield stress and plastic viscosity increases. One can also notice that, for the same $n$ value, the $\left(a_{s} / b\right)_{v}$ is higher at a higher $M_{s}$, while in most cases rheological parameters increase despite this fact, indicating other underlying phenomena, which will be discussed later. At the same $(w / s)_{m}$ and $M_{s}$, the rheological parameters decrease with an increase in $\mathrm{n}$, which is attributable to the increased amount of $\mathrm{MOH}$ solution added to increase $n$, and the consequent reduction in the volume fraction of solids provided by the activator. The only exception is the Na silicate-fly ash suspension at an $M_{s}$ of 1.5 and $(w / s)_{m}$ of $0.20\left(a_{s} / b\right.$ of 0.66) where an increase in $\mathrm{n}$ increases both the yield stress and plastic viscosity despite the fact that increasing $\mathrm{n}$ results in an increase in the volume of activator solution. This inconsistency is attributed to more significant changes in the Na-based activator solution viscosity as noted previously in Figure 2. Further, the increase in plastic viscosity with increasing $\left(a_{s} / b\right)_{v}$ in Na-silicate fly ash suspensions could have been augmented by the higher concentration of $\mathrm{Na}^{+}$present which decreases the absolute surface charge of fly ash and thus the steric forces.

To further investigate possible influences in these suspensions, and disconnect the influence of solids content provided by the activator on the rheological parameters, suspensions of fly ash in potassium silicate activator solutions were prepared where a constant $\left(a_{s} / b\right)_{v}$ ratio of 0.72 was maintained while 
varying $M_{s}$ and $n$. The results are presented in Figure 8 which shows the yield stress and plastic viscosity of the suspensions and the activation solution viscosity as a function of $\mathrm{M}_{\mathrm{s}}$. Similar trends as in Figure 4 are noted, where increasing $M_{s}$ results in increased yield stress and plastic viscosity. However, at a constant $\left(a_{s} / b\right)_{V}$, increasing $n$ increases both yield stress and plastic viscosity, especially at the higher $M_{s}$ value. This is opposite to what was observed in Figure 6(a) where the influence of $n$ and $\left(a_{s} / b\right)_{v}$ were confounded. It is noted from this figure that there is a strong correlation between the trends of activation solution viscosity and the plastic viscosity of the resultant suspension. This indicates that the dominant influence on the suspension viscosity is the viscosity of the suspending solution itself and the solids loading. Yield stress is also found to demonstrate similar trends as the activation solution viscosity when plotted as a function of $M_{s}$, for the suspension with an $n$ value of 0.05 . However, at an $n$ value of 0.03 , the activation solution viscosity barely changes with $\mathrm{M}_{\mathrm{s}}$ whereas the yield stress increase is significant. It can thus be postulated with reasonable certainty that the activation solution viscosity is a less dominant influence on yield stress. Yield stress of activated fly ash suspensions is thus dominated by influences of solid loading and particle interactions as is the general case for particulate suspensions, while the plastic viscosity is more strongly influenced by activation solution viscosity and solids loading.

353

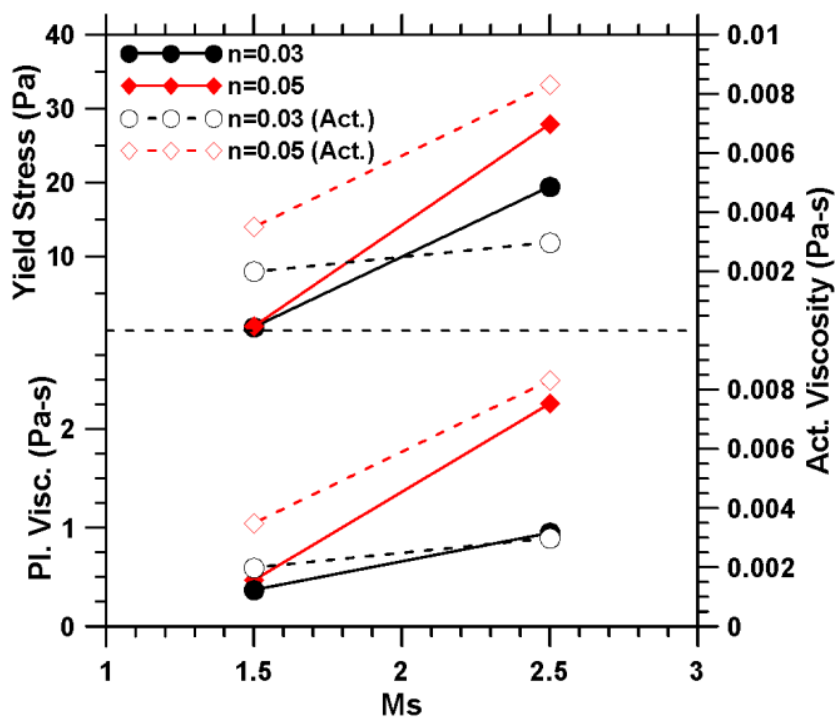

Fig. 7 Investigation of influence of $n$ and $M_{s}$ at a constant $\left(a_{s} / b\right)_{v}$ ratio of 0.72 . Solid lines represent the determined suspension rheological parameters, dashed lines represent rheological properties of activation solution.

\subsection{Rheological Response of Suspensions under Extended Shear Rates}

\subsubsection{Comparison of Activated Fly ash Suspensions to OPC-Water Suspensions}


The purpose of this section is to investigate the differences and/or similarities in rheological behavior of suspensions of fly ash particles in an alkaline activator to ordinary portland cement (OPC) particles in water. The experiments for this study, including that for the Type I/II OPC suspension were completed using the "wide" rheological procedure as presented in Section 2. This procedure allows for a model-less estimation of apparent yield stress (Barnes 1999; Vance et al. 2013) based on the stress plateau that is not discerned in the typical shear rate ranges employed in rheological studies of cementitious systems (Vance, Kirk 2014). Figures 8 and 9 present the flow (shear stress-shear rate) curves plotted in both linear and logarithmic scales to allow for more in-depth discussion of the rheological response of these suspensions. Solid loading in the various suspensions was adjusted so as to achieve flow curves that were roughly in the same shear stress range over the range of shear rates investigated (in a strain rate range of $5-100 / \mathrm{s}$ that is used in conventional rheological studies of cementitious suspensions) to facilitate comparison.
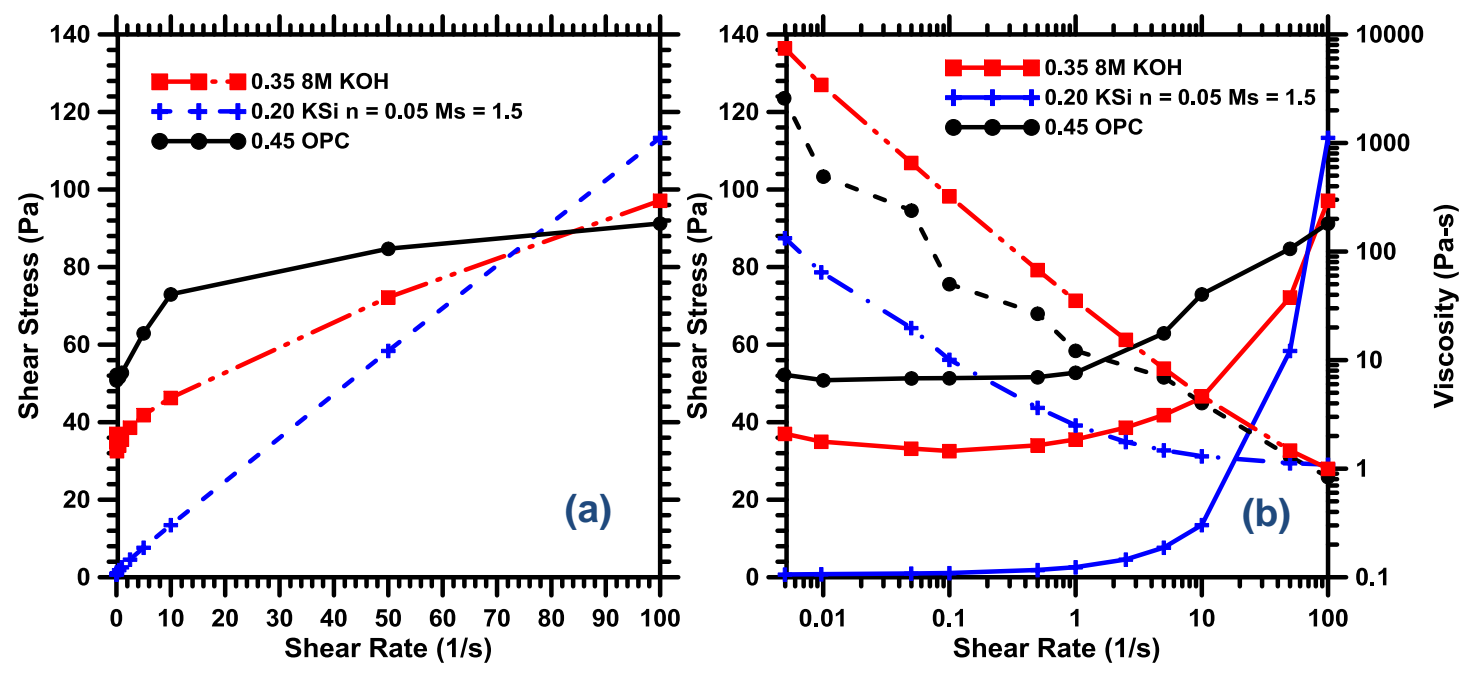

Fig. 8 Comparison of rheological response of fly ash suspensions in $\mathrm{KOH}$ and K-silicate solutions and 

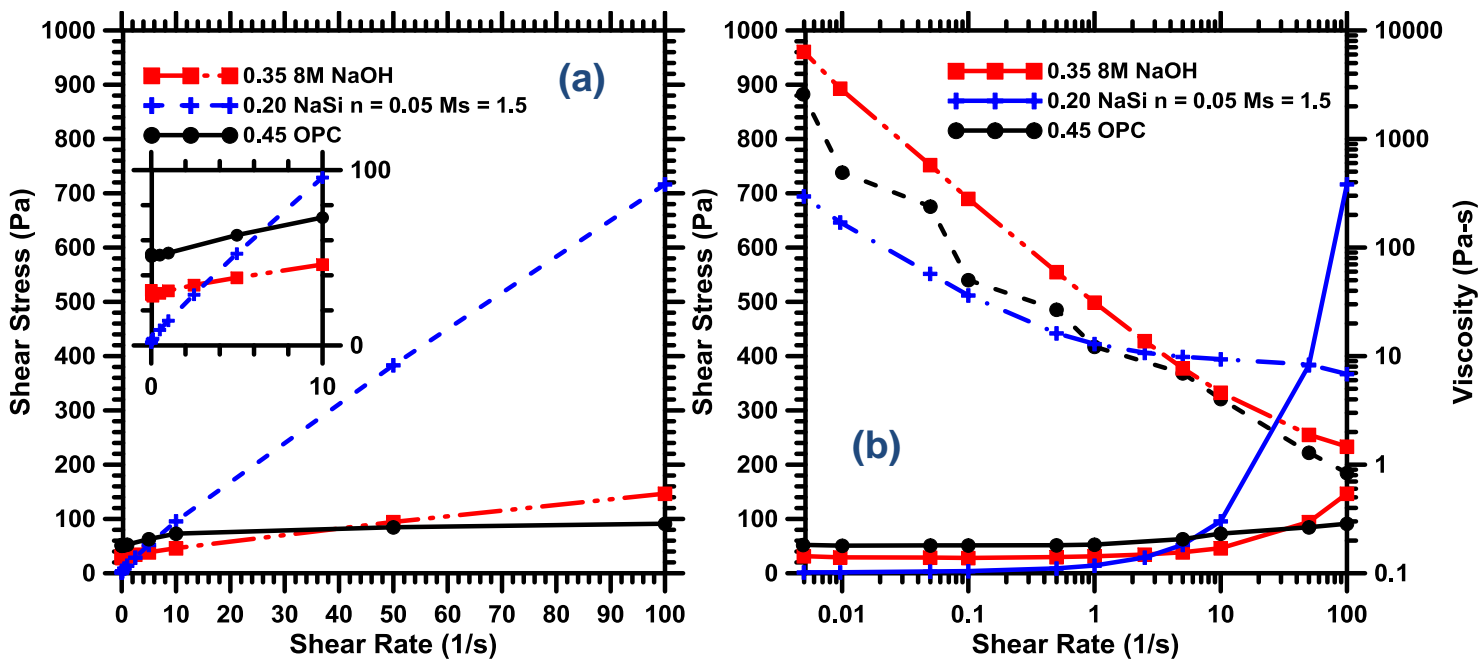

Fig. 9 Comparison of rheological response of fly ash suspensions in $\mathrm{NaOH}$ and $\mathrm{Na}$-silicate solutions and portland cement-water suspension: (a) shear stress response in linear scale and (b) shear stress (solid) and viscosity (dashed) response in logarithmic scale

It is evident from Figures 8 and 9 that the general shear rate-shear stress response of the fly ash-MOH suspensions is quite similar to that of the portland cement-water suspension. In both cases there is a stress plateau at lower shear rates (<1/s) indicating an apparent yield stress (Cheng 1986; Barnes 1999), which is preceded by a linear portion at relatively constant slope from shear rates of about 10 to 100/s. In the linear scale, both $\mathrm{KOH}$ and $\mathrm{NaOH}$ based suspensions show the typical downward trend at low shear rates that has been documented in several other publications of cementitious material rheology (Atzeni et al. 1985; Vance et al. 2013). In the $\mathrm{KOH}$-fly ash suspension, there is a noted upward trend in shear stress at the very low end of shear rates along the stress plateau region. This is indicative of flow instabilities associated with localized particle diffusion and reorganization (Schall and van Hecke 2009). As shear is applied to a suspension, localized particle rearrangement occur to enable flow, at very low shear rates, when there is insufficient strain to maintain, this localized reordering is destroyed and an instability in the flow curve results. The existence of the this trend in K-based suspensions and its absence in Na-based suspensions supports the presence of a higher surface charge on fly ash particles in K-based suspensions as compared to Na-based suspensions. This higher surface charge promotes the fly ash particles to move into the less concentrated region and to a less organized state to achieve a state of minimized energy (i.e., minimized interparticle repulsion), which results in an increased resistance to flow of the suspension indicated by an increase in stress (Callaghan 2008; Schall and van Hecke 2009).

\subsubsection{Discussions on the changes in rheological response with activator $M_{s}$}


The behavior of the silicate based activator suspensions is noted to be quite different as compared to the $\mathrm{MOH}$ activated systems. While the OPC and hydroxide-based suspensions demonstrate a viscosity range of about 4 orders of magnitude from the highest to lowest shear rate, the viscosity of the silicate based suspensions only increases by 2 orders of magnitude over the same shear rate range, as noted in Figures 8(b) and 9(b). Further, on a log scale, the viscosity-shear rate relationships of the OPC-water and fly ash$\mathrm{MOH}$ suspensions appears linear; while the silicate based suspensions demonstrate a viscosity asymptote at higher shear rates. To investigate the cause of this behavior, additional experiments were conducted using a mixture of fly ash and water with the same mass-based liquid to powder ratio as used in the silicate based activator experiments as shown in Figure 10.
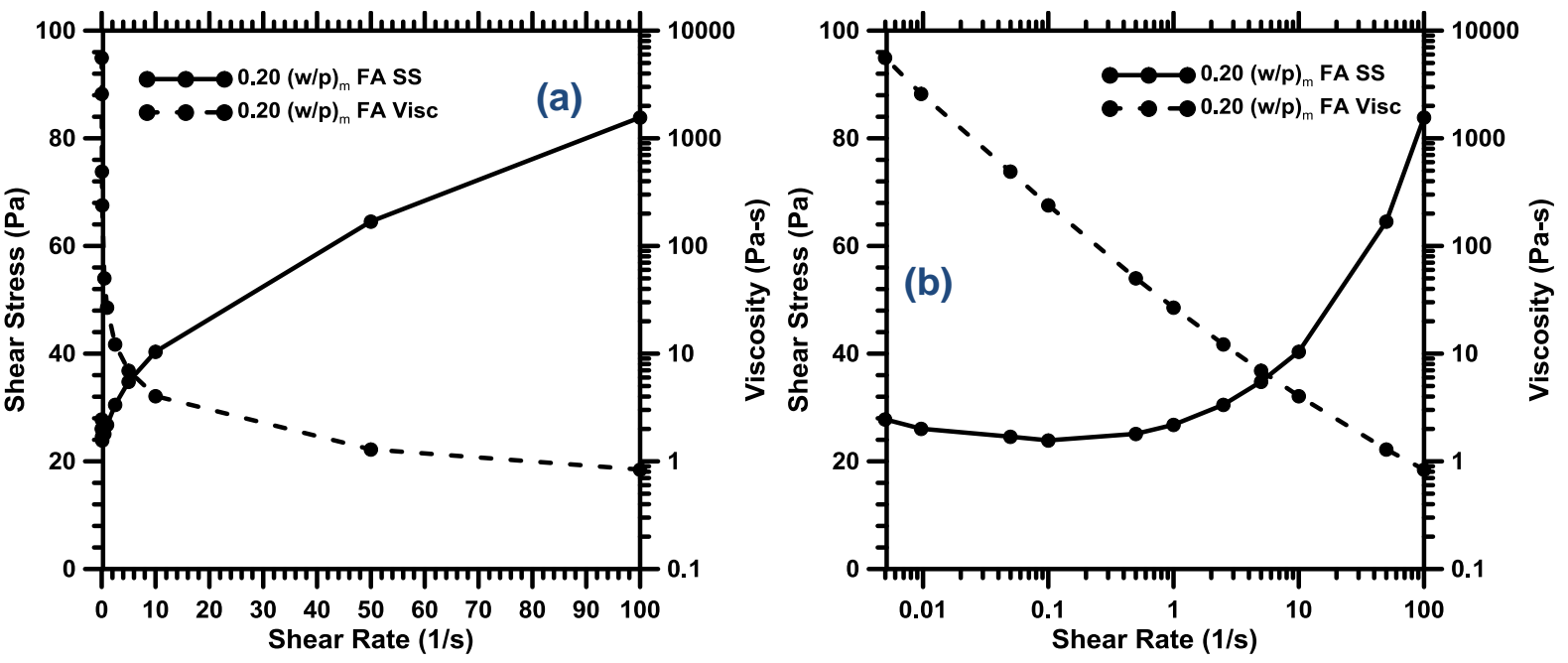

Fig. 10 Rheological study of $0.20(\mathrm{w} / \mathrm{s})_{\mathrm{m}}$ suspension of fly ash and water: (a) linear scale and (b) logarithmic scale. Shear stress (solid) and viscosity (dashed).

The fly ash-water suspension shows rheological behavior that bears more resemblance to that of the fly ash-MOH or OPC-water suspensions. In this case, a noted stress plateau and an increase in viscosity by almost 4 orders of magnitude over the range of shear rates investigated are observed. Given that the activation solutions in these suspensions have viscosities of 0.0017 and 0.0054 Pa-s (Figure 2) for potassium silicate and sodium silicate respectively, which are meaningfully greater than that of water (approximately $0.00089 \mathrm{~Pa}-\mathrm{s}$ at $25^{\circ} \mathrm{C}$ ), this behavior is counterintuitive. It can be noted from Figures 4 and 5 that at higher values of $\mathrm{M}_{s}$, in all suspensions investigated, the existence of an apparent yield stress is observed; i.e., the fly ash suspensions employing activators of higher $M_{s}$ are non-Newtonian. As the

417 Newtonian behavior is not present in fly ash-water suspensions, and it disappears at a higher value of $M_{s}$, this indicates a clear influence of the siliceous species and the free $\mathrm{M}^{+}$ion concentration present in the suspension. To better understand this, additional experiments were conducted at $M_{s}$ values of 1.0 and 2.0 
to investigate the range in which this phenomenon is present, as presented in Figure 11. At low $\mathrm{M}_{\mathrm{s}}$ values

421 (1.0 and 1.5), the Newtonian shift is visible with the absence of a stress plateau in Figure 11(a), while at

422 larger $M_{s}$ values, the behavior transitions to non-Newtonian as a stress plateau is formed. It is possible 423 that the increased quantity of hydroxide ions present in the solutions at lower values of $M_{s}$, results in a 424 decreased polymerization of the colloidal silica species as discussed previously. This in turn results in 425 colloidal species that may act in a fashion similar to superplasticizers in cement. When superplasticizers 426 are added to portland cement suspensions, the suspension transitions to shear thickening as indicated by an upward trend in the viscosity-shear rate plot. Fly ash suspensions in silica based activators indicate a shift towards shear-thickening behavior in Figures 8 and 9 as indicated by the significant decrease in 430 magnitude of viscosity reduction over the range of shear rates studied (Lootens et al. 2004; Papo and Piani 2004).
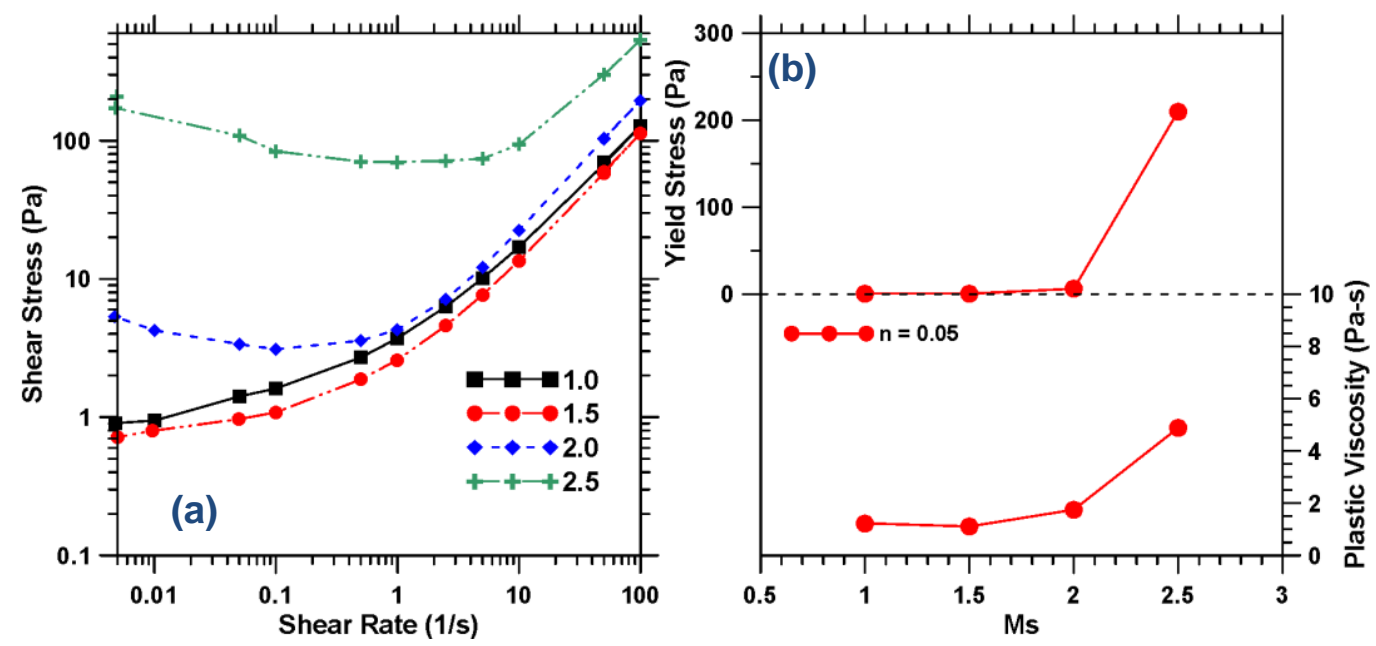

Fig. 11 - Rheological study of $0.25(\mathrm{w} / \mathrm{s})_{\mathrm{m}} \mathrm{K}-\mathrm{Si}$ fly ash suspension at varying $\mathrm{M}_{\mathrm{s}}$ : (a) flow curve in logarithmic scale and (b) influence of $\mathrm{M}_{\mathrm{s}}$ on determined rheological properties

\subsubsection{Response at different activator $M_{s}$ : Shear stress growth experiments}

A small amplitude oscillatory shear stress growth experiment was carried out on the fly ash - silicate suspensions corresponding to a $(\mathrm{w} / \mathrm{s})_{\mathrm{m}}$ of 0.25 . The results of this experiment are presented in Figure 12 which also shows the influence of reducing $M_{s}$ on the rheological behavior of the system. Noted from this figure is the significant change in behavior for the suspensions at a low $M_{s}$ with respect to both the storage and loss moduli. The storage modulus $\left(G^{\prime}\right)$ and loss modulus $\left(G^{\prime \prime}\right)$ are related to the elastic and viscous portions of a viscoelastic material respectively (Barnes et al. 2000; Nehdi and Rahman 2004). The expected trend in cementitious suspensions is a plateau region at low stress indicative of the linear viscoelastic region, followed by a significant decrease in both the storage and loss moduli at higher stresses, which 
indicates structural breakdown of the suspension (Nehdi and Rahman 2004). This low stress plateau is noted in all suspensions investigated except the K-Si suspension at an $M_{s}$ of 1.5, which is likely present at a further lower stress than that investigated in this study. Performing this experiment at further lower stresses resulted in increased data scatter due to the fact that the measured stresses were nearing the torque limit of the instrument, and hence they are not presented here. At lower $\mathrm{M}_{\mathrm{s}}$ values, the critical linear viscoelastic stress is shifted drastically to the left, and the height of the plateau region is an order of magnitude lower. The significantly higher storage modulus for the higher activator $M_{s}$ suspension indicates a more structurally organized system, which supports the observations and explanations discussed earlier. At an $\mathrm{M}_{\mathrm{s}}$ value of 1.5 there is a change in behavior of the suspension, possibly attributed to the charged colloidal siliceous species present in this system, or surface charge effects on the fly ash particles. Further, the drastic decrease in magnitude of the stress plateau and leftward shift of the critical linear viscoelastic stress is indicative of a behavior similar to that observed in OPC suspensions in the presence of high-range water reducing admixtures (Nehdi and Rahman 2004). A lower stress plateau is indicative of well-dispersed particles in a suspension with a less defined networked structure, likely caused by increased repulsive forces between fly ash particles. The exact nature of these phenomena requires future investigation, particularly in the context of understanding the solution chemistry of the alkalisilicate activator solutions. Given the noted inconsistencies in the use of superplasticizers in geopolymer suspensions (Palacios et al. 2009), an understanding of this phenomena may allow for optimization of the flow properties of geopolymer concretes without the use of chemical admixtures.
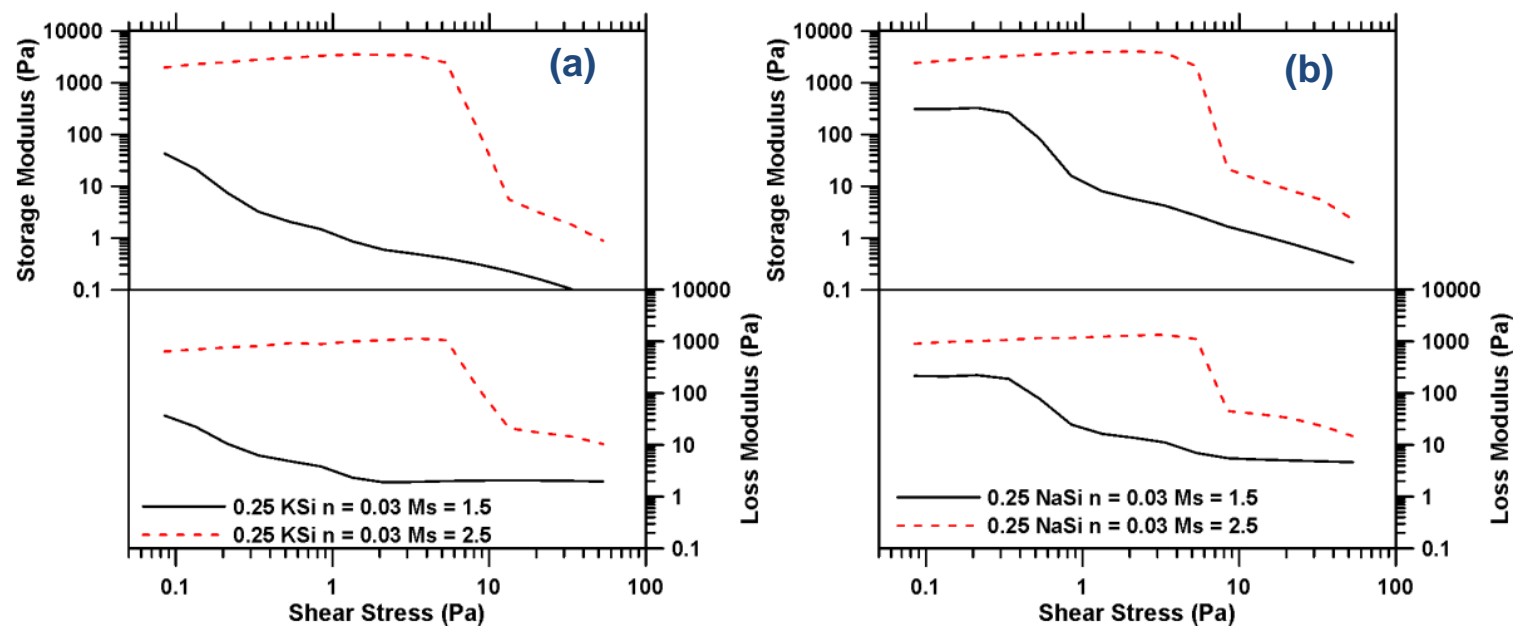

Fig. 12 Oscillatory shear study of $0.25(\mathrm{w} / \mathrm{s})_{\mathrm{m}}$ fly ash suspensions with (a) K-Si based activator, and (b)

\subsection{CONCLUSIONS}


The influence of activator type and concentration on the rheological characteristics of fly ash suspension

467 is reported. Hydroxides and silicates of $\mathrm{Na}$ and $\mathrm{K}$ were used as the activation solutions, the viscosities of which increased with molarity (for hydroxides) or $\mathrm{M}_{\mathrm{s}}$ (for silicates), with the Na-based activators demonstrating higher viscosities than their k-based counterparts. The rheological properties of $\mathrm{NaOH}$ or $\mathrm{KOH}$ activated fly ash were found to be primarily influenced by the changes in the viscosity of the suspending fluid and surface charge of the fly ash particles. Na-based suspensions demonstrated a large

472 increase in viscosity due to the more significant increase in the viscosity of the suspending fluid while K-

473 based suspensions showed a more significant increase in yield stress, attributed to the greater adsorption

474 of less well hydrated $\mathrm{K}^{+}$ions onto the surface of the fly ash particles, reducing the repulsive effect between

475 fly ash particles.

476 The rheological response of fly ash-alkali silicate suspensions were found to be complex. The yield stress and plastic viscosity of suspensions were observed to increase with $M_{s}$ with the yield stress tending to zero (i.e., approaching Newtonian behavior) at low activator $M_{s}$ values. Increasing the water-to-solids ratio and/or the $\mathrm{n}$ value of the suspension resulted in significantly different yield stress and plastic viscosity trends for the $\mathrm{Na}$ - and $\mathrm{K}$-based suspensions, pointing to the influence of both the activation solution viscosity and cationic adsorption on the fly ash particle surfaces that greatly influence the suspension rheology. Experiments on suspensions with controlled activation solution-to-binder ratios (volume-basis) showed the influence of several key parameters on the rheological properties. The plastic viscosity was found to be influenced strongly by the solid loading and the activation solution viscosity, while yield stress appears to be less influenced by activation solution viscosity and more strongly influenced by interaction effects produced by the surface charges on the fly ash particles, which are dependent on the cationic type.

In silicate based suspensions, for low $\mathrm{M}_{\mathrm{s}}$, the suspension demonstrated a transition to a Newtonian behavior, with a zero yield stress. While the OPC and hydroxide-based suspensions demonstrated a viscosity range of about 4 orders of magnitude from the highest to lowest shear rate (100/s to $0.005 / \mathrm{s})$, the viscosity of the silicate based suspensions increased by only 2 orders of magnitude over the same shear rate range. The fly ash-water suspension also behaved similar to the OPC-water and fly ash-MOH suspensions. A small amplitude oscillatory stress growth experiment showed that the critical linear viscoelastic stress plateau shifts to much lower shear stress ranges, and the storage/loss moduli reduces at lower $M_{s}$ values, akin to the response of superplasticized cementitious suspensions. The exact nature of this transition is not fully understood and requires additional work. 


\subsection{ACKNOWLEDGEMENTS}

The authors gratefully acknowledge the National Science Foundation (CMMI 1068985) and Arizona State University for the partial support of this research. The materials for this research were provided by Headwaters Resources and PQ Corporation, and are acknowledged. K.V. also acknowledges the Dean's Fellowship from the Ira A. Fulton Schools of Engineering at Arizona State University (ASU). This research was conducted in the Laboratory for the Science of Sustainable Infrastructural Materials (LS-SIM) at ASU and the authors gratefully acknowledge the support that has made this laboratory possible. The contents of this paper reflect the views of the authors who are responsible for the facts and accuracy of the data presented herein, and do not necessarily reflect the views and policies of the funding agency, nor do the contents constitute a standard, specification, or a regulation.

\section{BIBLIOGRAPHY}

Atzeni C, Massidda L, Sanna U (1985) Comparison between rheological models for portland cement pastes. Cem Concr Res 15:511-519. doi: 16/0008-8846(85)90125-5

Banfill PFG (2006) Rheology of fresh cement and concrete. Rheol Rev 2006:61.

Barnes HA (1999) The yield stress-a review or " $\pi \alpha v \tau \alpha ~ \rho \varepsilon \$$ Iota\$" - everything flows? J Non-Newton Fluid Mech 81:133-178.

Barnes HA (1989) Shear-thickening ("dilatancy") in suspensions of nonaggregating solid particles dispersed in Newtonian liquids. J Rheol 33:329.

Barnes HA, Non-Newtonian I of, Mechanics F (2000) A handbook of elementary rheology. Univ. of Wales, Institute of Non-Newtonian Fluid Mechanics

Bentz DP, Ferraris CF, Galler MA, et al. (2012) Influence of particle size distributions on yield stress and viscosity of cement-fly ash pastes. Cem. Concr. Res.

Bernal SA, Mejía de Gutiérrez R, Provis JL (2012) Engineering and durability properties of concretes based on alkali-activated granulated blast furnace slag/metakaolin blends. Constr Build Mater 33:99-108.

Bijen J (1996) Benefits of slag and fly ash. Constr Build Mater 10:309-314.

Bingham EC (1922) Fluidity and plasticity.

Brady JF (1993) The rheological behavior of concentrated colloidal dispersions. J Chem Phys 99:567-581.

Burgos-Montes O, Palacios M, Rivilla P, Puertas F (2012) Compatibility between superplasticizer admixtures and cements with mineral additions. Constr Build Mater 31:300-309.

Callaghan PT (2008) Rheo NMR and shear banding. Rheol Acta 47:243-255.

Cheng DC-H (1986) Yield stress: A time-dependent property and how to measure it. Rheol Acta 25:542554. doi: 10.1007/BF01774406 
Criado M, Palomo A, Fernández-Jiménez A, Banfill PFG (2009) Alkali activated fly ash: effect of admixtures on paste rheology. Rheol Acta 48:447-455.

Cyr M, Legrand C, Mouret M (2000) Study of the shear thickening effect of superplasticizers on the rheological behaviour of cement pastes containing or not mineral additives. Cem Concr Res 30:1477-1483. doi: 10.1016/S0008-8846(00)00330-6

Davidovits J (1999) Chemistry of geopolymeric systems, terminology. Geopolymer. pp 9-40

Davidovits J (2005) Geopolymer chemistry and sustainable development. The poly (sialate) terminology: a very useful and simple model for the promotion and understanding of green-chemistry. Proc. 2005 Geopolymer Conf. pp 9-15

Fernández-Jiménez A, Garcia-Lodeiro I, Palomo A (2007) Durability of alkali-activated fly ash cementitious materials. J Mater Sci 42:3055-3065.

Ferraris CF (1999) Measurement of the rheological properties of high performance concrete: state of the art report. J Res-Natl Inst Stand Technol 104:461-478.

Franks GV (2002) Zeta potentials and yield stresses of silica suspensions in concentrated monovalent electrolytes: isoelectric point shift and additional attraction. J Colloid Interface Sci 249:44-51.

Iler RK (1979) The chemistry of silica: solubility, polymerization, colloid and surface properties, and biochemistry.

Jeffrey DJ, Acrivos A (1976) The rheological properties of suspensions of rigid particles. AIChE J 22:417432.

Kamal MR, Mutel A (1985) Rheological Properties of Suspensions in Newtonian and Non-Newtonian Fluids. J Polym Eng 5:293-382. doi: 10.1515/POLYENG.1985.5.4.293

Krieger IM, Dougherty TJ (1959) A mechanism for non-Newtonian flow in suspensions of rigid spheres. Trans Soc Rheol 3:137-152.

Lootens D, Hébraud P, Lécolier E, Van Damme H (2004) Gelation, shear-thinning and shear-thickening in cement slurries. Oil Gas Sci Technol 59:31-40.

Lowke D (2009) Interparticle Forces and Rheology of Cement Based Suspensions. Nanotechnol. Constr. 3. Springer, pp 295-301

Mannheimer RJ (1983) Effect Of Slip On The Flow Properties Of Cement Slurries. Annu. Meet. Pap. Div. Prod.

Mikanovic N, Jolicoeur C (2008) Influence of superplasticizers on the rheology and stability of limestone and cement pastes. Cem Concr Res 38:907-919.

Mueller S, Llewellin EW, Mader HM (2010) The rheology of suspensions of solid particles. Proc R Soc Math Phys Eng Sci 466:1201-1228. doi: 10.1098/rspa.2009.0445 
Nägele E (1986) The Zeta-potential of cement: Part II: Effect of pH-value. Cem Concr Res 16:853-863.

Nägele E, Schneider U (1989) The zeta-potential of blast furnace slag and fly ash. Cem Concr Res 19:811820.

Nehdi M, Rahman M-A (2004) Effect of geometry and surface friction of test accessory on oscillatory rheological properties of cement pastes. ACI Mater. J. 101:

Palacios M, Houst YF, Bowen P, Puertas F (2009) Adsorption of superplasticizer admixtures on alkaliactivated slag pastes. Cem Concr Res 39:670-677.

Palomo A, Grutzeck MW, Blanco MT (1999) Alkali-activated fly ashes: a cement for the future. Cem Concr Res 29:1323-1329.

Papo A, Piani L (2004) Effect of various superplasticizers on the rheological properties of Portland cement pastes. Cem Concr Res 34:2097-2101.

Pasquino R, Nicodemi F, Vanzanella V, et al. (2013) A rheological phase diagram of additives for cement formulations. Rheol Acta 52:395-401.

Poulesquen A, Frizon F, Lambertin D (2013) Rheological behavior of alkali-activated metakaolin during geopolymerization. Cem.-Based Mater. Nucl. Waste Storage. Springer, pp 225-238

Provis JL, Muntingh Y, Lloyd RR, et al. (2007) Will Geopolymers Stand the Test of Time? Dev Porous Biol Geopolymer Ceram Ceram Eng Sci Proc 235.

Provis JL, Van Deventer JSJ (2009) Geopolymers: structure, processing, properties and industrial applications. Woodhead Cambridge, UK

Puertas F, Fernández-Jiménez A (2003) Mineralogical and microstructural characterisation of alkaliactivated fly ash/slag pastes. Cem Concr Compos 25:287-292.

Qing-Hua C, Sarkar SL (1994) A study of rheological and mechanical properties of mixed alkali activated slag pastes. Adv Cem Based Mater 1:178-184.

Ravikumar D, Neithalath N (2012b) Reaction kinetics in sodium silicate powder and liquid activated slag binders evaluated using isothermal calorimetry. Thermochim. Acta

Ravikumar D, Neithalath N (2012a) Effects of activator characteristics on the reaction product formation in slag binders activated using alkali silicate powder and $\mathrm{NaOH}$. Cem Concr Compos 34:809-818. doi: 10.1016/j.cemconcomp.2012.03.006

Saak AW, Jennings HM, Shah SP (2001) The influence of wall slip on yield stress and viscoelastic measurements of cement paste. Cem Concr Res 31:205-212.

Santamaria-Holek I, Mendoza Cl (2010) The rheology of concentrated suspensions of arbitrarily-shaped particles. ArXiv10055707 Cond-Mat 
612

613

614

615

616

617

618

619

620

621

622

Scales PJ, Johnson SB, Healy TW, Kapur PC (1998) Shear yield stress of partially flocculated colloidal suspensions. AIChE J 44:538-544.

Schall P, van Hecke M (2009) Shear bands in matter with granularity. Annu Rev Fluid Mech 42:67.

Škvára F, Kopecký L, Šmilauer V, Bittnar Z (2009) Material and structural characterization of alkali activated low-calcium brown coal fly ash. J Hazard Mater 168:711-720. doi: 10.1016/j.jhazmat.2009.02.089

Stebbins JF, Farnan I, Xue X (1992) The structure and dynamics of alkali silicate liquids: A view from NMR spectroscopy. Chem Geol 96:371-385.

Svensson IL, Sjöberg S, Öhman L-O (1986) Polysilicate equilibria in concentrated sodium silicate solutions. J Chem Soc Faraday Trans 1 82:3635-3646.

Sweeny KH, Geckler RD (1954) The Rheology of Suspensions. J Appl Phys 25:1135-1144. doi: doi:10.1063/1.1721828

Termkhajornkit P, Nawa T (2004) The fluidity of fly ash-cement paste containing naphthalene sulfonate superplasticizer. Cem Concr Res 34:1017-1024.

Tognonvi MT, Massiot D, Lecomte A, et al. (2010) Identification of solvated species present in concentrated and dilute sodium silicate solutions by combined $<$ sup $>29</$ sup $>$ Si NMR and SAXS studies. J Colloid Interface Sci 352:309-315.

Vance K, Kumar A, Sant G, Neithalath N (2013) The rheological properties of ternary binders containing Portland cement, limestone, and metakaolin or fly ash. Cem Concr Res 52:196-207. doi: 10.1016/j.cemconres.2013.07.007

Vance, Kirk (2014) Early Age Characterization and Microstructural Features of Sustainable Binder Systems for Concrete. PhD Dissertation, Arizona State University

Wijnen P, Beelen TPM, De Haan JW, et al. (1989) Silica gel dissolution in aqueous alkali metal hydroxides studied by ${ }^{29} \mathrm{Si}$ NMR. J Non-Cryst Solids 109:85-94.

(2013) ASTM C109-13. Standard Test Method for Compressive Strength of Hydraulic Cement Mortars Using 2-in. Cube Specimens.

(2011) ASTM C1738 - 11a. Standard Practice for High-Shear Mixing of Hydraulic Cement Paste. 